\title{
Research
}

\section{Trust and Intention to Comply with a Water Allocation Decision: The Moderating Roles of Knowledge and Consistency}

\author{
$\underline{\text { Joseph A. Hamm }}^{1,2}, \underline{\text { Lisa M. PytlikZillig }}^{1}, \underline{\text { Mitchel N. Herian }}^{1}$, Alan J. Tomkins ${ }^{1}, \underline{\text { Hannah Dietrich }}^{2,3} \operatorname{and~Sarah~Michaels~}^{1,4}$
}

\begin{abstract}
Regulating water resources is a critically important yet increasingly complex component of the interaction between ecology and society. Many argue that effective water regulation relies heavily upon the compliance of water users. The relevant literature suggests that, rather than relying on external motivators for individual compliance, e.g., punishments and rewards, it is preferable to focus on internal motivators, including trust in others. Although prior scholarship has resulted in contemporary institutional efforts to increase public trust, these efforts are hindered by a lack of evidence regarding the specific situations in which trust, in its various forms, most effectively increases compliance. We report the results of an experiment designed to compare the impacts of three trust-related constructs, a broad sense of trust in the institution, specific process-fairness perceptions, and a dispositional tendency to trust others, on compliance with water regulation under experimentally varied situations. Specifically, we tested the potential moderating influences of concepts relevant to water regulation in the real world: high versus low information conditions about an institutional decision, decision consistency with relevant data, and decision outcome valence. Our results suggest that participants' dispositional trust predicts their intent to comply when they have limited information about decisions, but the effects of dispositional trust are mediated by trust in the institution. Institutional trust predicts compliance under narrow conditions: when information is lacking or when decision outcomes are positive and are justified by available data. Finally, when the regulatory decision is inconsistent with other data in high-information conditions, prior judgments of institutional process fairness are most predictive of intent to comply. Our results may give guidance to water regulators, who may want to try to increase trust and thus increase voluntary compliance; the results suggest, in particular, that such efforts be tailored to the situation.
\end{abstract}

Key Words: compliance; human dimensions of natural resource management; procedural justice; trust; water allocation

\section{INTRODUCTION}

Water management is an essential component of the dynamic between humanity and the life-supporting ecosystems on which it depends. Through monitoring and allocation, water regulatory institutions in the United States (Hightower and Pierce 2008) and around the world (World Health Organization 2012) play vital roles in negotiating the relationship between society and ecosystems and among competing interests within society (Mullin 2009). Many factors affect how well regulators meet the challenges they face and their overall stewardship of water. For example, given the difficulty of detecting overappropriation of water, especially groundwater (e.g., Carmona-Garcia 2011, VarelaOrtega et al. 2011), water regulators often rely in large part upon the voluntary compliance of stakeholders (Wade 1988), making a comprehensive understanding of compliance behavior vital. Indeed, even the best regulatory schemes are undermined if they are routinely flouted.

Public compliance with institutions has been examined in a number of contexts, notably including the management of social-ecological systems (e.g., Ostrom 1990). Researchers across contexts distinguish between motivators for compliance that are external to the person and those that are internal (e.g., Kuperan and Sutinen 1998, Tyler 2006a).
External approaches are common in the context of governance and are characterized by the use of punishments for failure to comply and rewards for compliance (e.g., Hardin 1968). Although potentially effective, these external approaches usually require considerable institutional resources (Etzioni 2000) and, even when possible, paradoxically, they have the potential to decrease compliance (Nielsen and Mathiesen 2003, Willis 2005). It has therefore been argued that it is preferable to focus on internal motivations when possible (Ostrom 1998).

Research has consistently found that fostering trust in general and trust in regulators in particular is a promising approach to enhancing internally motivated compliance (e.g., Ostrom 1998, May 2004, De Cremer and Tyler 2005). More relevantly though, trust has been viewed as fundamental for comanaging ecosystems generally (Armitage et al. 2009, Berkes 2009), as well as for traditional water resource management (Flitcroft et al. 2009). Contemporary institutional efforts to increase public trust (e.g., Cvetkovich and Nakayachi 2007, Davenport et al. 2007, Lubell, 2007) are consistent with the importance of trust in the literature. However, the effective use of institutional resources for encouraging compliance is hindered by a lack of evidence-based guidance concerning the specific situations in which trust, in its various forms, will in fact

\footnotetext{
${ }^{1}$ University of Nebraska Public Policy Center, ${ }^{2}$ Department of Psychology, University of Nebraska-Lincoln, ${ }^{3}$ Center on Children, Families, and the Law, University of Nebraska-Lincoln, ${ }^{4}$ Department of Political Science, University of Nebraska-Lincoln
} 
increase compliance. Trust is likely not a unitary construct, and research results often diverge when they investigate different forms or facets of trust or related constructs (McEvily and Tortoriello 2011, PytlikZillig et al. 2012, Hamm et al. 2013). In our present paper, we examine three commonly studied trust-related constructs to identify their relative influence in experimentally manipulated situations: institutional trust, procedural fairness, and dispositional trust.

Across governance contexts, theories of trust postulate that as a specific institution is judged more trustworthy, e.g., having competence, integrity, legitimacy, and numerous other characteristics, individuals are more likely to respond positively to it (Scholz and Lubell 1998, Murphy 2004, Tyler 2006a, Stern 2008). Institutional trust has been found to be pertinent to governance generally (Chanley et al. 2000) as well as being pertinent in various natural resource settings (Cvetkovich and Winter 2003, Payton et al. 2005, Earle and Siegrist 2008, Stern 2008, Voinov and Gaddis 2008, Huang et al. 2010). Regarding natural resources management specifically, Winter and Cvetkovich (2010:218) conclude that trust in governance institutions affects the relationship between the institution and the trustor generally, but specifically influences "perceived efficacy and approval of planned or proposed [management] actions." Despite this postulated importance, one specific concern regarding institutional trust lies in its malleability. Some have noted that institutional trust might reflect overall evaluations of institutional performance, which can change over time (Gibson et al. 2003). Others have noted that institutional trust may be especially likely to be updated when negative outcomes are encountered (Poortinga and Pidgeon 2004), leading to the common complaint that trust is difficult to build but easy to destroy. The implication of such possibilities is that to the extent that institutional trust may be updated in response to specific situations, trust measured at one time may or may not be predictive of compliance at a later time. It is, therefore, possible that it could be less useful for water regulators and managers to invest in the development of broad perceptions of trust if it will be too easily destroyed by institutional decisions that trustors experience as negative, for example, restricting amount of water available for irrigation.

As part of understanding this broader notion of trust in institutions, researchers have also investigated a number of more specific constructs that have been shown to influence positive perceptions of and reactions to governance institutions. One such construct is perceptions of procedural fairness, or process fairness. Procedural fairness is a longstudied construct in social psychology (e.g., Thibaut and Walker 1975). Researchers have consistently shown that procedural fairness assessments are influenced by institutional factors such as neutrality, respectful treatment, and encouragement of stakeholders' voices (Lind and Tyler 1988, Tyler 1989, 2006a,b, Markell and Tyler 2008), and serve as heuristics by which institutions and their decision outcomes can be judged (Lind and van den Bos 2002). Within the context of natural resources governance, Syme et al. (1999) explored the components of fairness in water allocations and concluded that procedural fairness judgments were strong determinants of overall perceptions of regulatory decisions (see also Syme and Nancarrow 1997). Their conclusion has been corroborated by a growing body of research that shows that procedural fairness is an important construct for natural resource management generally (Kuperan and Sutinen 1998, Cvetkovich and Nakayachi 2007, Davenport et al. 2007, Earle and Siegrist 2008, Leahy and Anderson 2008).

Institutional trust and procedural fairness are often presumed to rely on some level of knowledge about the institution and its procedures. More limited public knowledge of institutions and their actions, however, is not uncommon. Because of this lack of more specific information, evaluations of the institution may be more influenced by broader evaluations, like dispositional trust, or trust in people generally. In this regard, dispositional trust operates like a personality trait; some people are more trusting and others less trusting. Within the context of natural resources specifically, Leahy and Anderson (2008) identify dispositional trust as a major theme in responses from participants who were asked to discuss their trust in and expectations of the United States Army Corps of Engineers in their area. Additionally, Lubell (2007) identified a significant association between dispositional trust and evaluations of specific institutions in a water allocation context. Notably, some research suggests that dispositional trust may be most important in situations in which the trustor has limited relevant knowledge (D'Amico 2003, see also Hamm et al. 2013).

Despite the interest in the role of trust and related constructs in increasing compliance, the relative efficacies of various trust-related constructs in experimentally varied natural resource situations have received only rather limited attention, but see Reeson et al. (2011) for an example of relevant work in behavioral economics and LePage et al. (2013) for a discussion of recent advances in agent-based simulation and modeling. Information about whether specific trust-related constructs are more or less related to compliance in the waterregulation context, and the extent to which their effects are dependent on characteristics of the specific situation is important. The current study evaluates the influence of three trust-related constructs, institutional trust, procedural fairness judgments, and dispositional trust, on compliance in situations that varied along three important dimensions. In water regulation contexts, people may have high versus low information about institutional decisions (level of information), the regulatory decisions may be viewed as positive or negative to one's personal situation (decision valence), and people may be faced with decisions that appear consistent or inconsistent with other relevant data (decision 
consistency). We expected that dispositional trust would have its greatest influence under low-information conditions, that institutional trust, assessed before the allocations were presented, would have lower predictive ability when the subsequent decision was negative rather than positive, and that procedural fairness judgments about the institution would lose influence when decisions were made in the face of evidence that seemed inconsistent with relevant data, potentially challenging the perceived fairness of the process.

The current research investigated these relationships in experimentally manipulated, simulated water-resource governance situations. Although laboratory studies have numerous limitations, especially those involving students rather than target populations, such studies provide a level of internal validity and efficiency difficult to match in real-world studies that are likely more ecologically valid (Aronson et al. 1990, Ostrom 2006).

\section{METHOD}

Eighty-six students from a large midwestern university, 58\% female and $80 \%$ Caucasian, with an average age of 20.2 years, were asked to complete an online water allocation survey via the psychology department's research website. The online survey included a description of a water allocation scenario that asked the participants to assume the role of an irrigating farmer. A variety of measures were embedded (see Fig. 1). Specifically, participants first completed a measure of dispositional trust (Step 1) before proceeding to read a basic explanation of concepts important to water allocation, e.g., definitions of over- and underappropriation of water (Step 2). In this step, participants also received very basic information about the regulatory agency that was responsible for allocating water in the area, specifically, about its responsibility to declare the local watershed over- or underappropriated, and then they completed a measure of trust in the water regulator (institutional trust, Step 3). Note that the water regulator was originally manipulated as a between-group variable (the Nebraska Department of Natural Resources or the local Natural Resource District), but no significant differences were identified between the regulatory agencies on any subsequent measures, indicating that, for the purposes of this study, our participants did not distinguish between them. We therefore collapsed across conditions for our analyses and for the remainder of this article will refer only to the "water regulator."

Next, information was presented about a hypothetical water quantity tool that was used by regulators to determine local water quantities (Step 4). Participants then were told that the water regulator had not yet made a final decision, but was likely to declare their watershed as overallocated, thereby reducing their personal allocation (Step 5, limited information allocation condition). To make this forecasted reduction salient, they were reminded that such reductions could harm
Fig. 1. Survey flow.
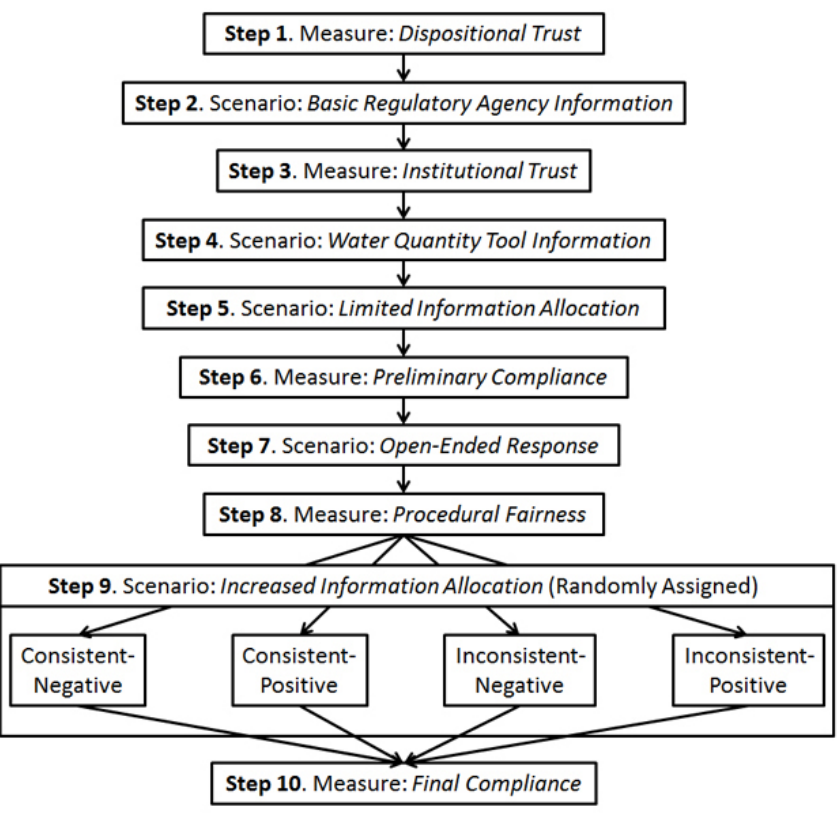

their yield, but they were not given any other additional explanatory information. Their initial intention to comply with this allocation was then measured (Step 6, preliminary compliance). Next, participants were given the opportunity to respond to an open-ended prompt in which they were asked to state whether they were for or against the decision to restrict water allocations and present their rationale (Step 7). The open-ended prompt was manipulated between groups, i.e., participants were randomly assigned to one of two conditions, to provide either a low opportunity to influence the decision (what they would say to their friends at a coffeehouse), or a high opportunity (what they would say to the water regulator at a town hall meeting). Perceptions of the institution's procedural fairness were measured next (Step 8). Note that although the open-ended manipulation was intended to influence procedural fairness assessments by affecting perceived influence on the regulation decision, no significant differences were identified between groups on any of the procedural fairness items, and so this manipulation was treated as a constant for the remainder of the manuscript. In Step 9, increased information condition, participants saw the water regulator's final allocation decision, which was either positive or negative (increased or decreased allocation, reflecting decision valence conditions) and consistent or inconsistent with information from the hypothetical water quantity tool, reflecting decision consistency conditions. Finally, participants' final intention to comply was measured (Step 10). The survey took an average of 48 minutes to complete. 


\section{Situational manipulations}

Within the survey flow, the first dimension, level of information, was manipulated as a within-group variable. In Step 5 of our procedures (Fig. 1), participants received no information about their water allocation in the scenario, other than that it was likely to be reduced in the future and that this reduction could hurt their yield. This low-information condition mimics many real-world allocations because, even when information about the reasons for water allocations is readily available, this kind of public policy information is often ignored by the general public (Delli Carpini and Keeter 1993). In Step 9 of our procedure, participants were offered additional information about the water allocation they were to receive. This higher-information condition also mimics real-world situations, because many regulatory agencies are working to increase their transparency by making the rationales and data upon which their decisions are based more available to the public.

The second dimension varied was the decision valence of the information presented in the higher-information condition (Step 9), in which the water allocation decision was manipulated to be either positive or negative for the participant. In the positive valence condition, participants were informed that "The actual final decision of the [water regulator] was to declare lifting (lessening) water restrictions on farmers in your area throughout the growing season." In the negative valence condition, participants were informed that the water regulator had decided "to declare additional water restrictions on farmers in your area throughout the growing season." This positive or negative allocation received by the participant was made in contrast to the outcome received by farmers in neighboring watersheds. Thus, in the positive outcome condition, the neighboring watersheds received more water restrictions (reduced water allocations), relative to the participant's watershed. Conversely, in the negative outcome condition, the neighboring watershed received a greater relative water allocation.

The third dimension, decision consistency, manipulated whether the additional information presented in Step 9, i.e., the higher-information condition, revealed a water allocation decision that was consistent or inconsistent with data available from the hypothetical water quantity tool described in Step 4 of the survey. In the data-consistent condition, the allocation decision was consistent with presented water quantity data: the decision would limit the water allocated when the water quantity tool indicated levels were low, or the decision would not limit the water when the levels were high. Conversely, in the data-inconsistent condition, the regulators' allocation decision was not consistent with the water quantity tool data, i.e., the decision limited the water allocated when the data showed that the levels were high or did not limit them when the levels were low.

\section{Measures}

Our primary dependent variable, intention to comply, was measured at two points in the survey to assess compliance under the various conditions. Preliminary compliance was measured in Step 6, using a single question, which asked participants, "How likely is it that you would follow any restrictions imposed by the [water regulator], even if it is likely to reduce your total crop yield" on a 0-10 scale, where higher numbers indicated a greater degree of compliance $(M=6.53$; $\mathrm{SD}=2.01)$. Final compliance was measured in Step $10 \mathrm{using}$ a question similar to the preliminary compliance question; it asked "If this were a real scenario, how likely is it that you would follow the policies set by the [water regulator]." It was scored on the same $0-10$ scale as the previous question $(M=$ 6.56; $\mathrm{SD}=2.19)$.

Participants completed measures of trust in the institution, procedural fairness perceptions, and dispositional trust; see Appendix 1 for all items. Trust in the institution was measured in Step 3 with an eight-item scale that included items relating to perceptions of competence, motivation, and legitimacy of the institution, as well as felt loyalty toward and obligation to obey the institution (see Appendix 1). The specific perceptions of procedural fairness were measured in Step 8 using an 11item scale, modified from one used in prior research (Bornstein et al. 2013); it focused on the decision makers' elements of voice, impartiality, and respect for the participant. Dispositional trust was measured in Step 1 using a three-item scale used in the General Social Survey (http://www3.norc. org/GSS+Website/Browse+GSS+Variables/) and the National Election Study (http://www.electionstudies.org/studypages/ cdf/anes_cdf_var.pdf) that asks participants to respond to their beliefs about the motivations of "most people" on 10-point bipolar scales labeled at the endpoints. The reliability of all of the scales was acceptable to high (institutional trust, Cronbach's $\alpha=0.89$; procedural fairness, $\alpha=0.89$; and dispositional trust, $\alpha=0.60$ ). Means of the items on each scale were computed and used in the subsequent analyses.

\section{RESULTS}

Analyses were conducted using the Statistical Package for the Social Sciences (IBM Corp. 2011). Before conducting multiple regression analyses, we examined the bivariate correlations between the preliminary compliance criterion, institutional trust, procedural fairness, and dispositional trust. Preliminary compliance was significantly correlated with both dispositional trust and trust in the institution, but not with procedural fairness (see Table 1). Next, to assess the suitability of our variables for linear multiple regression analysis, we evaluated the normality of our model residuals (error). Standardized and unstandardized residual skewness and kurtosis were less than $|0.5|$, indicating that the residual variances were roughly normal. 
Table 1. Descriptives and intercorrelations for primary measures.

\begin{tabular}{|c|c|c|c|c|c|c|}
\hline \multirow[t]{2}{*}{ Measure } & \multirow[t]{2}{*}{ Mean } & \multirow[t]{2}{*}{ Std. Dev. } & \multicolumn{4}{|c|}{ Pearson Correlations } \\
\hline & & & 1 & 2 & 3 & 4 \\
\hline 1. Preliminary Compliance (6) & 6.53 & 2.01 & - & & & \\
\hline 2. Final Compliance (10) & 6.56 & 2.19 & $0.51 * * *$ & - & & \\
\hline 3. Institutional Trust (3) & 3.59 & 0.67 & $0.34 * *$ & $0.30 * *$ & - & \\
\hline 4. Procedural Fairness (8) & 3.31 & 0.62 & 0.16 & $0.32 * *$ & $0.53 * * *$ & - \\
\hline 5. Dispositional Trust (1) & 4.88 & 1.49 & $0.27 *$ & 0.17 & $0.35^{* *}$ & $0.32 * *$ \\
\hline
\end{tabular}

Note. Correlations column headings refer to the scales in the correspondingly numbered rows. Dashes indicate 1.0 correlations between a construct and itself. Numbers in parentheses after a measure indicate the Figure 1 step at which it was assessed. $N$ s for the correlations $=73$ to 80 .

$* p<0.05, * * p<0.01, * * * p<0.001$

Next, we examined the predictive power of the trust-related constructs under low-information conditions by regressing preliminary compliance on all three predictors and their interactions. No three-way or two-way interactions were identified (all $p>0.17$ ) and procedural fairness perceptions were not significantly predictive alone or when other trust variables or their interactions were included as statistical controls. Thus, we next estimated a model that regressed preliminary compliance on only the two constructs with which it had significant bivariate associations, dispositional trust and institutional trust, to identify their independent influence. When both predictors were in the model, the bivariate association of preliminary compliance and dispositional trust was lost (see Table 2), suggesting that the effect of dispositional trust on preliminary compliance was potentially mediated by trust in the institution (Baron and Kenny 1986). Because dispositional trust is theorized to be a personality trait and therefore precedes institutional trust conceptually, as well as within the survey itself, a Sobel test was conducted that indicated that the indirect effect of dispositional trust on preliminary compliance was mediated by trust in the institution $(z=1.99, p<0.05)$.

Before examining the predictive power of the trust-related constructs under high-information conditions, we evaluated the effectiveness of the manipulations, i.e., Did participants notice the decision valence and consistency of the decision to the data? Participants were asked how fair or unfair the final decision was, how positive or negative the outcome was for the participant, and how positive or negative the outcome was for the farmers in the neighboring area. As expected, participants in the positive final allocation condition rated the decision as more positive for them $(M=4.28, \mathrm{SD}=1.32)$ than those in the negative allocation condition $(M=2.75, \mathrm{SD}=$ $1.18 ; F(1,77)=29.06, p=0.002)$. In addition, participants in the positive allocation condition saw the decisions as less positive for the farmers in the neighboring area $(M=3.07$, SD $=1.18)$, than did participants in the negative conditions $(M=$ $3.89, \mathrm{SD}=1 ; F(1,77)=9.34, p=0.003)$. Finally, participants in the data-consistent allocation conditions rated them as significantly more fair $(M=3.31, \mathrm{SD}=0.90)$ than those in the data-inconsistent conditions $(M=2.61, \mathrm{SD}=0.97 ; F(1,77)=$ $10.84, p<0.001)$.

Next, we examined the bivariate associations between final compliance, the trust-related constructs, and the situation variables in the higher-information condition. As hypothesized, final compliance was not correlated with dispositional trust, but was significantly associated with trust in the institution and perceptions of procedural fairness (see Table 1). Prior to dropping dispositional trust from further consideration, we tested its main and 2-way interactive effects with each of the other potential predictor variables. Because all effects were nonsignificant (all $p>0.40$ ), we dropped dispositional trust from subsequent models. Means tests with the situation variables indicated a significant difference in final compliance between decision consistency conditions, $F(1,77)$ $=4.22, p=0.04$, such that participants indicated more compliance in the data-consistent allocation condition $(M=$ $7.11, \mathrm{SD}=2.10)$ than in the data-inconsistent condition $(M=$ $6.11, \mathrm{SD}=2.19)$. However, no significant difference in compliance was identified between the positive (increased water) allocation condition $(M=6.86, \mathrm{SD}=2.35)$ and the negative (decreased water) allocation condition $(M=6.19$, SD $=1.97 ; F[1,77]=1.825, p=0.18)$.

As before, we next assessed the suitability of our variables for linear regression by evaluating the normality of our model residuals. Standardized and unstandardized residual skewness and kurtosis were less than $|0.7|$, again indicating that our residual variances were roughly normal. We next tested for the potential situationally specific relationships between our trust variables and compliance by regressing final compliance on institutional trust and procedural fairness perceptions, the decision consistency and decision valence variables, as well as their two-way interactions. In addition, because we were especially interested in the predictive ability of institutional trust and process fairness perceptions across contexts, we also included the 3-way interactions of decision consistency by 
Table 2. Preliminary compliance mediation model.

\begin{tabular}{|c|c|c|c|c|c|c|}
\hline \multirow[t]{2}{*}{ Predictor Variables } & \multicolumn{3}{|c|}{$\mathrm{CV}=$ Institutional Trust } & \multicolumn{3}{|c|}{$\mathrm{CV}=$ Preliminary Compliance } \\
\hline & $\beta$ & $B$ & $S E$ & $\beta$ & $B$ & $S E$ \\
\hline Dispositional Trust & $0.35 * * *$ & $0.16^{* * *}$ & 0.05 & 0.16 & 0.22 & 0.15 \\
\hline Institutional Trust & --- & --- & --- & $0.28 *$ & $0.85 *$ & 0.35 \\
\hline Constant & & 2.84 & 0.23 & & 2.41 & 1.21 \\
\hline Model Statistics & \multicolumn{3}{|c|}{$\begin{array}{c}\operatorname{adj} R^{2}=0.11, \\
F(1,81)=11.39 * *\end{array}$} & \multicolumn{3}{|c|}{$\begin{aligned} \operatorname{adj} R^{2} & =0.12, \\
F(2,77) & =6.15^{* *}\end{aligned}$} \\
\hline
\end{tabular}

$* p<0.05, * * p<0.01, * * * p<0.001, \mathrm{CV}=$ Criterion Variable, $\beta=$ standardized Beta,

$B=$ unstandardized coefficient, $S E=$ standard error.

valence by institutional trust, and decision consistency by valence by procedural fairness (see Table 3 ). The quantitative predictors were mean-centered because of the introduction of interaction terms (Aiken and West 1991), and dummy codes were used for valence ( $0=$ negative, $1=$ positive $)$ and consistency $(0=$ inconsistent, $1=$ consistent $)$. Results from this initial model indicated that the three-way interaction involving procedural fairness was not significant (see lefthand Initial Model columns in Table 3) but that the three-way interaction involving institutional trust was significant. To simplify the model, we dropped the nonsignificant three-way and the nonsignificant two-way interactions that were not implicated in the significant three-way interaction.

As shown in the right-hand columns of Table 3 , in the final model, the effect of procedural fairness depended on the consistency of the final decision with the data, as indicated by the significant procedural fairness by decision consistency interaction. The effects of institutional trust were dependent on both the consistency and valence of the final water allocation decision, as indicated by the significant three-way interaction between institutional trust, decision consistency, and decision valence. To interpret these interactions, we computed and tested the significance of the regression coefficients of institutional trust and perceived procedural fairness under each of the four final, higher-information decision conditions within the context of our final regression model. As shown in Table 4, when the final water allocation decision was consistent with recommendations suggested by the water quantity tool (consistency $=1$ ), prior specific procedural fairness judgments (controlling for trust in the institution) had no effect. However, when the decision was inconsistent (consistency $=0$ ), prior perceptions of procedural fairness had a strong positive effect on final compliance. Meanwhile, trust in the institution (controlling for specific procedural fairness perceptions) had no significant effect on compliance, except when the final allocation decision was both consistent with the data from the water quantity tool (consistency $=1$ ) and positively valenced (valence $=1$ ). Only under these relatively ideal conditions did institutional trust have a significantly strong and positive impact on participants' intention to comply.

\section{DISCUSSION}

In the current study, we provide a step toward understanding the potential roles of trust in voluntary compliance with water allocations. By investigating the potential moderating influence of the amount of information that participants had about institutional decisions, decision valence, and its consistency with relevant data, we were able to examine the relative effects of three trust-related constructs. We found that when participants had little information about why a decreased allocation decision was forecast, intent to comply was predicted by dispositional trust, and the effect of dispositional trust was mediated by trust in the institution. This finding makes intuitive sense. Because compliance decisions cannot be based upon information the participant does not have, they must be based on something else. The data from the current study suggests that, in these cases, undifferentiated dispositions to trust others may influence compliance, at least under the conditions we studied. The mediation of this effect by trust in the institution suggests that, like compliance, evaluations of the institution, e.g., trust in the institution, are likely to be driven by dispositional trust in the absence of other information about the institution (D'Amico 2003). Indeed, in our analyses, dispositional trust alone accounted for $10 \%$ of the variance in institutional trust (Table 2). Thus, our data suggest that when a person has no more specific information upon which to base perceptions of an institution, he or she will trust and comply with it to the extent that he or she generally trusts people.

When participants were given additional information about an actual, rather than forecast, allocation decision, the 
Table 3. Final compliance regression models.

\begin{tabular}{|c|c|c|c|c|c|c|}
\hline \multirow[t]{2}{*}{ Predictor Variables } & \multicolumn{3}{|c|}{ Initial Model } & \multicolumn{3}{|c|}{ Final Model } \\
\hline & $\beta$ & $B$ & $S E$ & $\beta$ & $B$ & $S E$ \\
\hline \multicolumn{7}{|l|}{ Main effects } \\
\hline Institutional Trust (IT) & 0.05 & 0.18 & 0.72 & 0.02 & 0.08 & 0.71 \\
\hline Procedural Fairness (PF) & $0.54 *$ & $1.93 *$ & 0.91 & $0.74 * *$ & $2.64 * *$ & 0.64 \\
\hline Decision Consistency (DC) & $0.42 *$ & $1.85^{*}$ & 0.77 & $0.41 *$ & $1.82 *$ & 0.76 \\
\hline Decision Valence (DV) & 0.11 & 0.49 & 0.62 & 0.11 & 0.51 & 0.62 \\
\hline \multicolumn{7}{|l|}{ 2-way interactions } \\
\hline $\mathrm{PF} * \mathrm{DC}$ & -0.46 & -2.38 & 1.35 & $-0.66^{* *}$ & $-3.43 * *$ & 0.91 \\
\hline $\mathrm{PF} * \mathrm{DV}$ & 0.32 & 1.50 & 1.36 & --- & --- & --- \\
\hline $\mathrm{IT} * \mathrm{PF}$ & 0.17 & 0.55 & 0.47 & 0.23 & 0.73 & 0.44 \\
\hline $\mathrm{IT} * \mathrm{DC}$ & -0.13 & -0.68 & 1.52 & -0.08 & -0.41 & 1.47 \\
\hline $\mathrm{IT} * \mathrm{DV}$ & -0.45 & -2.16 & 1.30 & -0.34 & -1.63 & 1.20 \\
\hline $\mathrm{DC} * \mathrm{DV}$ & -0.33 & -1.63 & 1.01 & -0.34 & -1.66 & 1.00 \\
\hline \multicolumn{7}{|l|}{ 3-way interactions } \\
\hline $\mathrm{PF} * \mathrm{DC} * \mathrm{DV}$ & -0.31 & -1.99 & 1.85 & --- & --- & --- \\
\hline $\mathrm{IT} * \mathrm{DC} * \mathrm{DV}$ & $0.79 *$ & $4.80 *$ & 2.07 & $0.67 *$ & $4.05 *$ & 1.90 \\
\hline Constant & & 5.79 & 0.43 & & 5.81 & 0.43 \\
\hline Model Statistics & \multicolumn{3}{|c|}{$\begin{array}{c}\operatorname{adj} R^{2}=0.256, \\
F(12,60)=3.06^{* *}\end{array}$} & \multicolumn{3}{|c|}{$\begin{array}{c}\operatorname{adj} R^{2}=0.263, \\
F(10,62)=3.58^{* *}\end{array}$} \\
\hline
\end{tabular}

$* p<0.05, * * p<0.01, \beta=$ standardized beta, $B=$ unstandardized coefficient, $S E=$ standard error

undifferentiated trusting tendencies (dispositional trust) no longer predicted intention to comply. Instead, projected compliance appeared to be driven by the participants' more specific evaluations of the institution itself, broad trust in the institution, and specific assessments of process fairness. When the available data failed to support the final allocation decision, prior specific perceptions of procedural fairness, assessed after reading about the forecast water allocation reduction, but before learning about the actual final decision, had a positive effect on compliance. Thus, when participants believed that the institution would treat them fairly even though a water reduction had been decided, they appeared to be somewhat inoculated against the negative effects of the data inconsistency on their reported compliance. On the other hand, those who perceived the institution as low in process fairness before receiving a data-inconsistent allocation decision reported the lowest compliance intentions, regardless of the valence of the decision.

In addition, when data were consistent with the final decision, compliance was generally higher overall, and prior perceptions of procedural fairness ceased to have a significant impact on compliance. In light of the recent tendency of regulatory institutions to make information publicly available, these findings suggest there may, indeed, be risks associated with decisions in which the regulated person feels that the data do not support the decision: specifically, those who already question the institution's fairness may be less likely to comply. However, the findings also imply that there are benefits to an institution of having previously established a reputation for procedural fairness under challenging conditions. To the extent that an institution can enhance procedural fairness perceptions prior to a data-inconsistent decision, the institution may increase the likelihood that the public will comply when an inconsistent situation arises. Investments in general, broad, and perhaps unchallenged trust in the institution, however, may not pay off as usefully in such situations. In the current study, the only decision situation under which this broad sense of initial institutional trust predicted compliance in the face of more information was when the outcome was consistent and positive, i.e., water allocations were increased and supported by the data.

Regarding valence and procedural fairness, our results suggest that fairness effects may not be dependent on whether the allocation is comparatively good or bad for the regulated person. This finding is consistent with studies in the procedural fairness literature (e.g., Tyler 2006a) that find the fairness of the procedures used matters and prompts individuals who do not obtain the outcomes they desire to nonetheless rate the experience higher. Although much of this work was conducted with criminal defendants, the fairness findings have been 
Table 4. Situationally specific prediction of final compliance by institutional confidence and perceived procedural fairness.

\begin{tabular}{|c|c|c|c|c|c|c|}
\hline \multirow[t]{2}{*}{ Decision features } & \multicolumn{3}{|c|}{ Institutional Trust } & \multicolumn{3}{|c|}{ Procedural Fairness } \\
\hline & $\beta$ & $B$ & $S E$ & $\beta$ & $B$ & $S E$ \\
\hline Data-inconsistent $\&$ negative & 0.02 & 0.08 & 0.71 & $0.74 * *$ & $2.64 * *$ & 0.64 \\
\hline Data-inconsistent \& positive & -0.46 & -1.55 & 0.96 & $0.74 * *$ & $2.64 * *$ & 0.64 \\
\hline Data-consistent \& negative & -0.10 & -0.34 & 1.32 & -0.22 & -0.79 & 0.63 \\
\hline Data-consistent \& positive & $0.62 * *$ & $2.09 * *$ & 0.75 & -0.22 & -0.79 & 0.63 \\
\hline
\end{tabular}

** $p<0.01, \beta=$ standardized Beta, $B=$ unstandardized Beta, $S E=$ standard error.

robust enough to suggest this may be pertinent to water allocation determinations, where actual outcomes for water users are frequently not what water users desire.

\section{LIMITATIONS AND SPECULATION}

Despite the contribution of laboratory studies such as this, our research has limitations. First, instead of measuring actual compliance in a sample of people currently subject to the regulations discussed, this study measured intention to comply in a student sample, using manipulated hypothetical scenarios. We chose these methods to emphasize control and internal validity (Campbell 1957). Our resultant experimental control allows some confidence that the differences in predictive ability are the result of the information manipulations as all other potential influences were held constant, or at least were randomly distributed. Nonetheless, our choices leave unanswered the important question of whether associations between trust and compliance for students in hypothetical situations will exist in more relevant populations that are making real-world decisions, e.g., farmers and landowners. Although the generalizability of our results to real-world populations and situations must be tested in future research, application of the theory of reasoned action (e.g., Ajzen 1991) provides a potentially compelling argument for why these student results might generalize to more relevant, real-world samples. The theory postulates that behavioral intention, an important driver of actual behavior, is itself driven both by evaluations of the outcome of the behavior and by subjective norms. We have no reason to believe that this broadly applicable theory would not apply to both students and farmers. Although persons subject to regulation may have responsibilities and more tangible dependencies on water that are quite different than those of students, open-ended responses from student participants indicated that they were at least cognizant of the outcome evaluations of actual regulated persons, such that while they are certainly an imperfect proxy, they are likely a close approximation; e.g., one student wrote, "I feel that I might follow them most of the time but if my crops NEED water I would feel obligated to my family to keep the crop healthy so I can make money, and not lose money."
Second, the use of our hypothetical scenarios precludes discussion about direct and interactive influences of other potential drivers of compliance. Explicit and implicit pressures from peers and local norms, lack or presence of the resources necessary to comply, and existing personal relationships were not manipulated in our scenarios. Additionally, the survey method itself has the potential to create artificial drivers of responses. For example, it is well known that survey participants are motivated to be consistent across responses (Falk and Zimmermann 2012). Further, real-life scenarios may contain less ambiguity than surveys. Our measure of preliminary compliance simply informed participants that the water allocation was likely to reduce their crop yield. It is unclear from our results if participants assumed that this reduction would be significant and so intended to fail to comply, or trivial and reported an intention to comply.

Despite these limitations, what lends value to our results for real-world water regulators is their consistency with previous research and theory. Our results add to a compelling argument regarding the existence of a relationship between compliance and trust-related constructs generally. Across settings (lab and real-world), contexts (water regulation, conservation, and legal directives), and kinds of data (qualitative and quantitative), research consistently finds associations between trust and compliance (see Ostrom 2006 for an argument about the importance of using multiple methods in the context of common pool resources management). Our replication of this effect is useful because it experimentally tests the effects of the constructs under situations of practical importance to water regulation.

\section{CONCLUSION AND RECOMMENDATIONS}

Trust is recognized as an essential component of best practices for managing natural resources (Armitage et al. 2009, Berkes 2009). Of the many trust-related constructs discussed in the natural resources literature, institutional trust, process fairness perceptions, and dispositional trust are among the most common. Indeed, qualitative studies that simply ask participants to discuss their trust in a natural resources institution consistently identify these three as important 
themes in responses (Davenport et al. 2007, Leahy and Anderson 2008). As argued by other researchers and suggested by our results here, however, the influence of these trustrelated constructs depends on the situation (e.g., Cvetkovich and Nakayachi 2007, Earle and Siegrist 2008, Herian et al. 2012). Our research tested the influence of three potential moderators of these constructs and found important effects for each conceptualization under different situations. Specifically, dispositional trust appears to be most important when the participant's relevant knowledge is low. Our results suggest that the influence of institutional trust and procedural justice are moderated by decision valence and the consistency of the decision to relevant data, such that institutional trust is predictive only in limited situations, when positively valenced and consistent with relevant data, but that procedural justice is predictive when the decision is inconsistent with the relevant data.

From our results, we offer some specific recommendations for natural resources managers. Regarding the measurement of trust, we argue for specificity in operationalization and conceptualization (e.g., Smith et al. 2013). Depending on how trust is operationalized, e.g., as a disposition, broad attitude, or specific evaluation, its effects in different situations may vary. Regarding the trust-related constructs most important for managers, our results suggest managers might be well served by focusing on public perceptions, especially perceptions of procedural fairness. Natural resources management institutions are unlikely to have much influence over the trait-level trusting tendencies of the public, but our results indicate that with even relatively little information (approximately a paragraph in our scenario), the influence of dispositional trust can become nonsignificant. In these situations, with the exception of situations involving dataconsistent negatively valenced decisions, compliance was more strongly predicted by the more institution-specific constructs of trust in the institution and by perceived process fairness. These constructs are well within the influence of natural resource managers. Working to increase regulated individuals' trust in the institution is likely to positively influence compliance in the best of situations. Attention to fair procedures is also likely to be useful in many situations, but especially when decisions must be made in the face of potentially or ostensibly disconfirming evidence, a very real consideration, given the expectation of increasing variability in water availability as a function of climate change (Gleick 2012).

Responses to this article can be read online at: http://www.ecologyandsociety.org/issues/responses. php/5849

\section{Acknowledgments:}

The authors gratefully acknowledge the feedback of the editor, of two anonymous reviewers, and of Dr. Craig Allen and Dr. Brian H. Bornstein on previous versions of this manuscript. This research was supported in part by the National Science Foundation (NSF) under Grant Numbers IIS-0535255 and SES-1061635. In addition, Joseph Hamm's participation was supported in part by an NSF IGERT fellowship, DGE-0903469. Any opinions, findings, and conclusions or recommendations expressed in this material are those of the authors and do not necessarily reflect the views of the National Science Foundation.

\section{LITERATURE CITED}

Aiken, L. S., and S. G. West. 1991. Multiple regression: testing and interpreting interactions. Sage, Newbury Park, California, USA.

Ajzen, I. 1991. The theory of planned behavior. Organizational Behavior and Human Decision Processes 50:179-211. http://dx.doi.org/10.1016/0749-5978(91)90020T

Armitage, D. R., R. Plummer, F. Berkes, R. I. Arthur, A. T. Charles, I. J. Davidson-Hunt, A. P. Diduck, N. C. Doubleday, D. S. Johnson, M. Marschke, P. McConney, E. W. Pinkerton, and E. K. Wollenberg. 2009. Adaptive co-management for social-ecological complexity. Frontiers in Ecology and the Environment 7(2):95-102. http://dx.doi.org/10.1890/070089

Aronson, E., P. C. Ellsworth, J. M. Carlsmith, and M. H. Gonzales. 1990. Methods of research in social psychology. McGraw-Hill, New York, New York, USA.

Baron, R. M., and D. A. Kenny. 1986. The moderator-mediator variable distinction in social psychological research: conceptual, strategic, and statistical considerations. Journal of Personality and Social Psychology 51(6):1173-1182. http:// dx.doi.org/10.1037/0022-3514.51.6.1173

Berkes, F. 2009. Evolution of co-management: role of knowledge generation, bridging organizations and social learning. Journal of Environmental Management 90:1692-1702. http://dx.doi.org/10.1016/j.jenvman.2008.12.001

Bornstein, B. H., A. J. Tomkins, E. M. Neeley, M. N. Herian, and J. A. Hamm. 2013. Reducing courts' failure-to-appear rate by written reminders. Psychology, Public Policy, and the Law 19:70-80. http://dx.doi.org/10.1037/a0026293

Campbell, D. T. 1957. Factors relevant to the validity of experiments in social settings. Psychological Bulletin 54(4): 297-312. http://dx.doi.org/10.1037/h0040950

Carmona-Garcia, G. 2011. Development of a participatory DSS for the impact assessment of future scenarios and water 
management options. Application to the Guadiana Basin in Spain. Dissertation. Agricultural University of Madrid, Madrid, Spain.

Chanley, V. A., T. J. Rudolph, and W. M. Rahn. 2000. The origins and consequences of public trust in government: a time series analysis. Public Opinion Quarterly 64:239-256. http:// dx.doi.org/10.1086/317987

Cvetkovich, G., and K. Nakayachi. 2007. Trust in a highconcern risk controversy: a comparison of three concepts. Journal of Risk Research 10:223-237. http://dx.doi. org/10.1080/13669870601122519

Cvetkovich, G., and P. L. Winter. 2003. Trust and representations of the management of threatened and endangered species. Environment and Behavior 35:286-307. http://dx.doi.org/10.1177/0013916502250139

D'Amico, L. C. 2003. Examining determinants of managerial trust: evidence from a laboratory experiment. Paper presented at the 10 October 2003 National Public Management Research Conference, Washington, D.C., USA. http://www.pmranet. org/conferences/georgetownpapers/DAmico.pdf

Davenport, M. A., J. E. Leahy, D. H. Anderson, and P. J. Jakes. 2007. Building trust in natural resource management within local communities: a case study of the Midewin National Tallgrass Prairie. Environmental Management 39:353-368. http://dx.doi.org/10.1007/s00267-006-0016-1

De Cremer, D., and T. R. Tyler. 2005. Managing group behavior: the interplay between procedural fairness, sense of self, and cooperation. Pages 151-218 in M. Zanna, editor. Advances in experimental social psychology. Academic, New York, New York, USA.

Delli Carpini, M. X., and S. Keeter. 1993. Measuring political knowledge: putting first things first. American Journal of Political Science 37:1179-1206. http://dx.doi.org/10.2307/2111549

Earle, T. C., and M. Siegrist. 2008. On the relation between trust and fairness in environmental risk management. Risk Analysis 28:1395-1414. http://dx.doi.org/10.1111/

j.1539-6924.2008.01091.x

Etzioni, A. 2000. Social norms: internalization, persuasion, and history. Law and Society Review 34:157-178. http://dx. doi.org/10.2307/3115119

Falk, A., and F. Zimmermann. 2012. A taste for consistency and survey response behavior. CESifo Economic Studies 59 (1):181-193. http://dx.doi.org/10.1093/cesifo/ifs039

Flitcroft, R. L., D. C. Dedrick, C. L. Smith, C. A. Thieman, and J. P. Bolte. 2009. Social infrastructure to integrate science and practice: the experience of the Long Tom Watershed Council. Ecology and Society 14(2): 36. [online] URL: http:// www.ecologyandsociety.org/vol14/iss2/art36/
Gibson, J. L., G. A. Caldeira, and L. K. Spence. 2003. Measuring attitudes towards the United States Supreme Court. American Journal of Political Science 47:354-367. http://dx. doi.org/10.1111/1540-5907.00025

Gleick, P. 2012. The water of the United States: freshwater availability and use. Pages 3-22 in J. Christian-Smith and P. H. Gleick, editors. A 21st century US water policy. Oxford University Press, New York, New York, USA.

Hamm, J. A., L. M. PytlikZillig, M. N. Herian, B. H. Bornstein, A. J. Tomkins, and L. Hoffman. 2013. Deconstructing public confidence in state courts. Journal of Trust Research 3(1): 11-31. http://dx.doi.org/10.1080/21515581.2013.771501.

Hardin, G. 1968. The tragedy of the commons. Science 162:1243-1248. http://dx.doi.org/10.1126/science.162.3859.1243

Herian, M. N., J. A. Hamm, A. J. Tomkins, and L. M. Pytlik Zillig. 2012. Public participation, procedural fairness, and evaluations of local governance: the moderating role of uncertainty. Journal of Public Administration Research and Theory 22:815-840. http://dx.doi.org/10.1093/jopart/ mur064

Hightower, M., and S. A. Pierce. 2008. The energy challenge. Nature 452:285-286. http://dx.doi.org/10.1038/452285a

Huang, L., K. Sun, J. Ban, and J. Bi. 2010. Public perception of blue-algae bloom risk in Hongze Lake of China. Environmental Management 45:1065-1975. http://dx.doi. org/10.1007/s00267-010-9480-8

IBM Corp. 2011. IBM SPSS Statistics for Windows, Version 20.0. IBM Corp., Armonk, New York, USA.

Kuperan, K., and J. G. Sutinen. 1998. Blue water crime: deterrence, legitimacy, and compliance in fisheries. Law \& Society Review 32:309-338. http://dx.doi.org/10.2307/827765

Leahy, J. E., and D. H. Anderson. 2008. Trust factors in community-water resource management agency relationships. Landscape and Urban Planning 87:100-107. http://dx.doi. org/10.1016/j.landurbplan.2008.05.004

LePage, C., D. Bazile, N. Becu, P. Bommel, F. Bousquet, M. Etienne, R. Mathevet, V. Souchere, G. Trebuil, and J. Weber. 2013. Agent-based modeling and simulation applied to environmental management. Pages 499-540 in B. Edmonds and R. Meyer, editors. Simulating social complexity, understanding complex systems. Springer-Verlag, Berlin, Germany.

Lind, E. A., and T. R. Tyler. 1988. The social psychology of procedural justice. Springer, New York, New York, USA. http://dx.doi.org/10.1007/978-1-4899-2115-4

Lind, E. A., and K. van den Bos. 2002. When fairness works: toward a general theory of uncertainty management. Research 
in Organizational Behavior 24:181-223. http://dx.doi. org/10.1016/S0191-3085(02)24006-X

Lubell, M. 2007. Familiarity breeds trust: collective action in a policy domain. Journal of Politics 69:237-250. http://dx.doi. org/10.1111/j.1468-2508.2007.00507.x

Markell, D., and T. R. Tyler. 2008. Using empirical research to design government citizen participation processes. University of Kansas Law Review 57:1-38.

May, P. J. 2004. Compliance motivations: affirmative and negative bases. Law and Society Review 38:41-68. http://dx. doi.org/10.1111/j.0023-9216.2004.03801002.x

McEvily, B., and M. Tortoriello. 2011. Measuring trust in organisational research: review and recommendations. Journal of Trust Research 1:23-63. http://dx.doi. org/10.1080/21515581.2011.552424

Mullin, M. 2009. Governing the tap: special district governance and the new local politics of water. MIT Press, Cambridge, Massachusetts, USA. http://dx.doi.org/10.7551/ mitpress/9780262013130.001.0001

Murphy, K. 2004. The role of trust in nurturing compliance: a study of accused tax avoiders. Law Human Behavior 28:187-209. http://dx.doi.org/10.1023/B:LAHU.0000022322.94776. ca

Nielsen, J. R., and C. Mathiesen. 2003. Important factors influencing rule compliance in fisheries: lessons from Denmark. Marine Policy 27:409-416. http://dx.doi. org/10.1016/S0308-597X(03)00024-1

Ostrom, E. 1990. Governing the commons: the evolution of institutions for collective action. Cambridge University Press, New York, New York, USA. http://dx.doi.org/10.1017/ CBO9780511807763

Ostrom, E. 1998. A behavioral approach to the rational choice theory of collective action: presidential address. American Political Science Review 92:1-22. http://dx.doi.org/10.2307/2585925

Ostrom, E. 2006. The value-added of laboratory experiments for the study of institutions and common-pool resources. Journal of Economic Behavior \& Organization 61:149-163. http://dx.doi.org/10.1016/j.jebo.2005.02.008

Payton, M. A., D. C. Fulton, and D. H. Anderson. 2005. Influence of place attachment and trust on civic action: a study at Sherburne National Wildlife Refuge. Society \& Natural Resources 18:511-528. http://dx.doi.org/10.1080/08941920590947940

Poortinga, W., and N. F. Pidgeon. 2004. Trust, the asymmetry principle, and the role of prior beliefs. Risk Analysis 24:1475-1486. http://dx.doi.org/10.1111/j.0272-4332.2004.00543. $\underline{\mathrm{X}}$
PytlikZillig, L. M., A. J. Tomkins, M. N. Herian, J. A. Hamm, and T. Abdel-Monem. 2012. Public input methods and confidence in government. Transforming Government: People, Process and Policy 6:92-111. http://dx.doi. org/10.1108/17506161211214840

Reeson, A. F., J. G. Tisdell, and R. R. J. McAllister. 2011. Trust, reputation, and relationships in grazing rights markets: an experimental economic study. Ecological Economics 70:651-658. http://dx.doi.org/10.1016/j.ecolecon.2010.10.013

Scholz, J. T., and M. Lubell. 1998. Trust and taxpaying: testing the heuristic approach to collective action. American Journal of Political Science 42:398-417. http://dx.doi.org/10.2307/2991764

Smith, J. W., J. E. Leahy, D. H. Anderson, and M. A. Davenport. 2013. Community/agency trust: a measurement instrument. Society \& Natural Resources: An International Journal 26(4):472-477. http://dx.doi.org/10.1080/08941920.2012 .742606

Stern, M. J. 2008. The power of trust: toward a theory of local opposition to neighboring protected areas. Society \& Natural Resources 21:859-875. http://dx.doi.org/10.1080/08941920801973763

Syme, G. J., and B. E. Nancarrow. 1997. The determinants of perceptions of fairness in the allocation of water to multiple uses. Water Resources Research 33:2143-2152. http://dx.doi. org/10.1029/97WR01504

Syme, G. J., B. E. Nancarrow, and J. A. McCreddin. 1999. Defining the components of fairness in the allocation of water to environmental and human uses. Journal of Environmental Management 57:51-70. http://dx.doi.org/10.1006/jema.1999.0282

Thibaut, J. W., and L. Walker. 1975. Procedural justice: a psychological analysis. Earlbaum, Hillsdale, New Jersey, USA.

Tyler, T. R. 1989. The psychology of procedural justice: a test of the group-value model. Journal of Personality and Social Psychology 57:830-838. http://dx.doi.org/10.1037/0022-3514.57.5.830

Tyler, T. R. 2006a. Psychological perspectives on legitimacy and legitimation. Annual Review of Psychology 57:375-400. http://dx.doi.org/10.1146/annurev.psych.57.102904.190038

Tyler, T. R. 2006b. Does the American public accept the rule of law? The findings of psychological research on deference to authority. DePaul Law Review 56:661-694.

Varela-Ortega, C., I. Blanco-Gutierrez, C. H. Swartz, and T. E. Downing. 2011. Balancing groundwater conservation and rural livelihoods under water and climate uncertainties: an integrated hydro-economic modeling framework. Global Climate Change 21:604-619.

Voinov, A., and E. J. B. Gaddis. 2008. Lessons for successful participatory watershed modeling: a perspective from 
modeling practitioners. Ecological Modelling 216:197-207. http://dx.doi.org/10.1016/j.ecolmodel.2008.03.010

Wade, R. 1988. The management of irrigation systems: how to evoke trust and avoid prisoner's dilemma. World Development 16:489-500. http://dx.doi.org/10.1016/0305-750X (88)90199-4

Willis, J. J. 2005. Transportation versus imprisonment in eighteenth- and nineteenth-century Britain: penal power, liberty, and the state. Law and Society Review 39:171-210. http://dx.doi.org/10.1111/j.0023-9216.2005.00080.x

Winter, P. L., and G. T. Cvetkovich. 2010. Trust mediates conservation-related behaviors. Ecopsychology 2:211-219. http://dx.doi.org/10.1089/eco.2010.0046

World Health Organization. 2012. UN-Water global annual assessment of sanitation and drinking-water (GLAAS) 2012 report: the challenge of extending and sustaining services. World Health Organization, Geneva, Switzerland. [Online] URL: http://whqlibdoc.who.int/publications/2012/9789241$\underline{503365 \text { eng.pdf }}$ 
Appendix 1. All trust items.

$\underline{\text { Trust in the Institution }}$

1. I have confidence in [the water regulator] to do their jobs and perform their functions as they should.

2. The leaders and staff of [the water regulator] are competent to perform their functions and meet their responsibilities.

3. There are plenty of reasons to believe that the leaders and staff of [the water regulator] are motivated to do their jobs and fulfill their responsibilities.

4. I feel a sense of loyalty to [the water regulator].

5. Even in the face of difficulty I am committed to supporting [the water regulator].

6. People should follow the decisions and policies of [the water regulator] even when they disagree with them.

7. [The water regulator] was established through lawful procedures.

8. [The water regulator] is a legitimate authority on surface water use and regulation.

\section{Procedural Fairness}

1. I feel like the decision makers are listening to my opinions.

2. I can freely express my points of view to decision makers.

3. I believe that my statements and views would influence the final decision made by the decision makers in this scenario.

4. The decision makers treat me with dignity and respect.

5. I think the decision makers will act in the interest of some groups over others.

6. I think that the influence of my opinion in this decision is similar to the influence of other people.

7. I think the decision makers have farmers' best interests in mind while making this decision.

8. I think the decision makers are using fair procedures to make their decision.

9. I think the decision makers respect my rights.

10.I think that public interest will be served by the final decision.

11.I feel that I have input in the decision making process in this scenario.

\section{Dispositional Trust}

1. Generally speaking, would you say that most people can be trusted, or that you can't be too careful?

2. Do you think that most people would try to take advantage of you if they got the chance, or would they try to be fair?

3. Would you say that most of the time people try to be helpful or that they are mostly looking out for themselves? 